\title{
ANÁLISE DE VIABILIDADE DE INVESTIMENTO PARA UMA MICROEMPRESA NO MUNÍCIPIO DE PIRAPOZINHO/SP, UM ESTUDO DE CASO.
}

\author{
Mário Antonio Franco Bôa Sorte, Jorge Gama da Silva Junior \\ Universidade do Oeste Paulista - UNOESTE. Curso de Ciências Contábeis, Presidente Prudente - SP. E-mail: \\ boasorte@unoeste.br
}

\section{RESUMO}

A avaliação de investimento é realizada com a intenção de verificar a integridade do negócio em que se esta aplicando o capital com a finalidade de retornos lucrativos, realizando projeções possíveis deste retorno. Este sistema traz maior eficiência e confiança ao empresário que deseja iniciar ou expandir seu negócio, pois através do mesmo, é presumido atingir melhores resultados. Deste modo este artigo tem como objetivo, averiguar a viabilidade de um investimento em uma empresa estabelecida na cidade de Pirapozinho - SP. Especificamente, demonstrou a rentabilidade do negócio, desenvolveu um sistema de custo confiável para esta avaliação e através do ponto de equilíbrio apontou o esforço necessário para que a empresa gere os lucros almejados. Trata-se de um estudo exploratória, descritiva, de abordagem quantitativa, ancorado em um estudo de caso desenvolvido através de uma pesquisa de mercado.

Palavras-chave: Análise de investimento, Custos, Formação de preços.

\section{ANALYSIS OF INVESTMENT FEASIBILITY FOR MICROENTERPRISE IN PIRPAPOZINHO County / SP, A CASE STUDY.}

\begin{abstract}
The investment evaluation is performed with the intention of checking the integrity of the business being applied in capital in order to profit returns, making possible return of the projections. This system brings greater efficiency and confidence to the businessman who want to start or expand your business, because through it, is presumed to achieve better results. Thus this article aims, to determine the feasibility of an investment in a company established in the city of Pirapozinho - SP. Specifically, demonstrated the profitability of the business, has developed a reliable system cost for this assessment and through the break-even made the effort required for the company to generate the desired profits. This is an exploratory, descriptive study with a quantitative approach, anchored in a case study developed through market research.
\end{abstract}

Keywords: Investment Analysis, Cost, price formation. 


\section{INTRODUÇÃO, JUSTIFICATIVA E METODOLOGIA}

Na constituição de uma empresa com fins lucrativos, deve ser analisado que ao decorrer de seu processo essa organização irá consumir recursos para a obtenção desse objetivo, tal seja o lucro. Sejam esses recursos monetários, humanos, materiais, tecnológicos entre outros, dessa forma, torna-se responsabilidade dos sócios saciar o gasto gerado através do consumo desses recursos. (FREZATTI, 2008)

Observando desta forma a importância de reconhecer esses futuros recursos e analisar seus respectivos gastos, juntamente vinculados com os seus valores gerados e verificando-se pela sua diferença, os possíveis resultados para a empresa, que sejam lucros ou prejuízos.

A competitividade criada no mercado para as micro e pequenas empresas, com as demais organizações de maior porte e com maiores recursos é de suma importância. Assim como diz Coronado $(2013$, p.5) "Pesquisas desenvolvidas com a finalidade de apontar as causas da extinção dessas empresas demonstram que, quanto maiores os empreendimentos, melhores serão as suas possibilidades de sucesso".

Desta forma, na intenção de melhor planejamento do negócio, julga-se necessária a avaliação do investimento, por meio de índices, quocientes e relatórios, realizados de modo técnico e fundamentados.

Neste contexto, este artigo tem como objetivo, averiguar a viabilidade de um investimento em uma microempresa estabelecida no município de Pirapozinho/SP. Busca especificamente, demonstrar a rentabilidade do negócio, desenvolvendo um sistema de custo confiável para esta avaliação, apontando a importância do ponto de equilíbrio, demonstre o esforço necessário para que a empresa gere os lucros almejados.

O estudo foi desenvolvido por meio da abordagem quantitativa e configura-se como uma pesquisa de caráter exploratório e descritivo, desenvolvido através de estudo de caso, e também de uma analise e interpretação de literatura relativa ao tema.

\section{FUNDAMENTAÇÃO E ANÁLISE DOS DADOS}

A pesquisa desenvolveu-se para analisar a possível implantação de um negócio no seguimento alimentício, dentro do município de Pirapozinho/SP. Para tanto, foram efetuada entrevista com o futuro empresário para que tornar-se mais sólido o conhecimento a respeito do negócio e seguimento de mercado. 
Tais pesquisas deram suporte ao levantamento de dados necessários para iniciar-se o desenvolvimento do estudo de viabilidade, de onde foram levantadas características inerentes ao produto que ora seria objeto de produção e comercialização posterior.

O produto em questão trata-se de uma esfiha aberta, e na tabela abaixo se demonstra os itens que compõe os custos de sua produção.

Tabela 1. COMPOSIÇÃO DOS INGREDIENTES

\begin{tabular}{l|r}
\hline \multicolumn{1}{c|}{ Ingredientes da massa } & Quantidades para produção de 35unidades \\
\hline Farinha de trigo & 1,00 \\
\hline Óleo & 0,20 \\
\hline Fermento & 0,05 \\
\hline Sal & 0,02 \\
\hline Açúcar & 0,10 \\
\hline
\end{tabular}

Fonte: Desenvolvido pelos autores

Averiguadas tais quantidades para produção, posteriormente fez-se necessário conhecer demais gastos que seriam envolvidos na produção, onde se obteve os gastos com gás, energia elétrica, água, combustível, empregado, telefone, matéria prima, e materiais diretos e embalagens.

Ademais far-se-ia necessárias às previsões de vendas, onde também se verificou que a produção era caracterizada por mais de um item, conforme tabela abaixo.

Tabela 2. PREVISÃO DE VENDAS

\begin{tabular}{l|r|r}
\hline \multicolumn{1}{c|}{ Produtos } & \% em vendas & \multicolumn{2}{c}{ Produção } \\
\hline Carne & $30,00 \%$ & 5.400 \\
\hline Frango & $20,00 \%$ & 3.600 \\
\hline Calabresa & $10,00 \%$ & 1.800 \\
\hline Pizza & $30,00 \%$ & 5.400 \\
\hline Queijo & $10,00 \%$ & 1.800 \\
\hline Totais & $100,00 \%$ & 18.000 \\
\hline
\end{tabular}

Fonte: Desenvolvido pelos autores

Entretanto, sendo a produção composta por mais de um item, torna-se obrigatório mais duas etapas no processo de elaboração dos custos de produção, sendo assim, custo da massa e dos ingredientes comuns que são inerentes a cada sabor e o custo dos ingredientes principais, que são específicos para cada sabor. 
Levantaram-se as quantidades e os valores, ressaltasse que os valores em questão foram à época da pesquisa, necessários para o custo de produção de cada etapa, como apresentados na tabela a seguir.

Tabela 3. CUSTOS DOS INGREDIENTES DA MASSA

\begin{tabular}{|c|c|c|c|c|}
\hline $\begin{array}{l}\text { Ingredientes da } \\
\text { massa }\end{array}$ & $\begin{array}{c}\text { Receita } 35 \text { para } \\
\text { unidades }\end{array}$ & $\begin{array}{l}\text { Valor } \\
\text { item }\end{array}$ & $\begin{array}{c}\text { Custo para } 35 \\
\text { unidades }\end{array}$ & $\begin{array}{l}\text { Custo } \\
\text { unitário }\end{array}$ \\
\hline Farinha de trigo- $\mathrm{kg}$ & 1,00 & $\mathrm{R} \$ 1,78$ & $\mathrm{R} \$ 1,78$ & $\mathrm{R} \$ 0,051$ \\
\hline Óleo- L & 0,20 & $R \$ 2,39$ & $\mathrm{R} \$ 0,48$ & $R \$ 0,014$ \\
\hline Fermento- kg & 0,05 & $R \$ 3,00$ & $\mathrm{R} \$ \mathbf{0 , 1 5}$ & $R \$ 0,004$ \\
\hline Sal- kg & 0,02 & $R \$ 1,83$ & $R \$ 0,04$ & $R \$ 0,001$ \\
\hline Açúcar- kg & 0,10 & $R \$ 2,70$ & $R \$ 0,27$ & $R \$ 0,008$ \\
\hline Total & & & $\mathrm{R} \$ 2,71$ & $\mathrm{R} \$ \quad 0,08$ \\
\hline
\end{tabular}

Fonte: Desenvolvido pelos autores

Tabela 4. CUSTOS DOS INGREDIENTES COMUNS

\begin{tabular}{l|c|r|r}
\hline \multicolumn{1}{c|}{ Ingredientes comuns } & Utilização diária & Custo para 900 unidades & \multicolumn{1}{c}{ Custo unitário } \\
\hline Limão & $4 \mathrm{~kg}$ & $\mathrm{R} \$ 3,00$ & 0,013333333 \\
\hline Tomate & $4 \mathrm{~kg}$ & $\mathrm{R} \$ 5,00$ & 0,02222222 \\
\hline Cheiro verde & $1,25 / \mathrm{maço}$ & $\mathrm{R} \$ 2,00$ & 0,002777778 \\
\hline Cebola & $0,6 \mathrm{~kg}$ & $\mathrm{R} \$ 1,50$ & 0,001666667 \\
\hline Queijo & $6 \mathrm{~kg}$ & $\mathrm{R} \$ 13,75$ & 0,091666667 \\
\hline Totais & & & $\mathrm{R} \$ 0,13$ \\
\hline
\end{tabular}

Fonte: Desenvolvido pelos autores

Tabela 5. CUSTOS DOS INGREDIENTES PRINCIPAIS

\begin{tabular}{l|r|r|r}
\hline \multicolumn{1}{c|}{ Ingredientes principais } & Valor $1 \mathrm{~kg}$ & Produção & \multicolumn{1}{c}{ Valor Unitário } \\
\hline Carne & $\mathrm{R} \$ 7,50$ & 50 & $\mathrm{R} \$ 0,15$ \\
\hline Frango & $\mathrm{R} \$ 6,00$ & 35 & $\mathrm{R} \$ 0,17$ \\
\hline Calabresa & $\mathrm{R} \$ 11,50$ & 65 & $\mathrm{R} \$ 0,18$ \\
\hline Pizza (presunto + queijo) & $\mathrm{R} \$ 17,25$ & 100 & $\mathrm{R} \$ 0,17$ \\
\hline Queijo & $\mathrm{R} \$ 13,50$ & 50 & $\mathrm{R} \$ 0,27$ \\
\hline
\end{tabular}

Fonte: Desenvolvido pelos autores

Após o levantamento dos custos de produção, que são valores dos insumos usados na fabricação dos produtos da empresa (BORNIA, 2009, p. 15), a próxima etapa no processo da análise no estudo de viabilidade é efetuar-se o cálculo do ponto de equilíbrio, que servirá como base para que se verifiquem as quantidades mínimas a serem produzidas e vendidas para que a empresa não incorra em prejuízos, conforme nos ensina VICECONTI e NEVES (2010, p.141) “o 
ponto de equilíbrio é a quantidade mínima que a empresa deve produzir para que não tenha prejuízo".

No intuito de se calcular o ponto de equilíbrio, o que se apura com a equação gastos fixos dividido pela margem de contribuição unitária ( $\mathrm{PE}=\mathrm{CF} / \mathrm{MCu}$ ), torna-se indispensável à separação dos gastos em fixos e variáveis, e para melhor compreensão se dá definições para cada deles, como seja, custo fixo é o qual não se altera em função da produção e/ou vendas, e custo variável é o que em função da produção e/ou vendas ocorre sua alteração.

Conforme ensinamentos de BRUNI e FAMÁ (2008, p.30):

(...) fixos: são custos que, em determinado período de tempo e em certa capacidade instalada, não variam, qualquer que seja o volume de atividade da empresa. Existem mesmo que não haja produção.

Variáreis: seu valor total altera-se diretamente em função das atividades da empresa. Quanto maior a produção, maiores serão os custos variáveis.

Após se efetuar as devidas separações, custos fixos e variáveis, pode-se obter a tabela a seguir:

Tabela 6. CUSTOS DOS PRODUTOS

\begin{tabular}{l|r|r|r|r|r|r}
\hline Produtos & $\begin{array}{c}\text { Custo } \\
\text { massa/un. }\end{array}$ & $\begin{array}{c}\text { Ingredientes } \\
\text { comuns/un. }\end{array}$ & $\begin{array}{c}\text { Ingredientes } \\
\text { Principais/un. }\end{array}$ & $\begin{array}{c}\text { Custo } \\
\text { variável/un. }\end{array}$ & $\begin{array}{c}\text { Quantidade } \\
\text { vendida }\end{array}$ & $\begin{array}{c}\text { Custo } \\
\text { variável }\end{array}$ \\
\hline Carne & 0,08 & 0,13 & 0,15 & 0,36 & 5400 & $1.939,82$ \\
\hline Frango & 0,08 & 0,13 & 0,17 & 0,38 & 3600 & $1.370,36$ \\
\hline Calabresa & 0,08 & 0,13 & 0,18 & 0,39 & 1800 & 695,07 \\
\hline Pizza & 0,08 & 0,13 & 0,17 & 0,38 & 5400 & $2.061,32$ \\
\hline Queijo & 0,08 & 0,13 & 0,27 & 0,48 & 1800 & 862,61 \\
\hline Totais & & & & 1,99 & 18000 & $6.929,18$ \\
\hline
\end{tabular}

Fonte: Desenvolvido pelos autores

Tabela 7. COMPOSIÇÃO DOS CUSTOS FIXOS

\begin{tabular}{l|r}
\hline \multicolumn{1}{c|}{ Custo fixo } & \multicolumn{1}{c}{ Custo fixo por mês } \\
\hline Gás & 370,00 \\
\hline Energia & 70,00 \\
\hline Agua & 35,00 \\
\hline Mão de obra & $2.781,14$ \\
\hline Total & $3.256,14$ \\
\hline
\end{tabular}

Fonte: Desenvolvido pelos autores

Apurou-se a margem de contribuição por meio do desenvolvimento da demonstração de resultado demonstrado na tabela a seguir: 
Tabela 8. DEMONSTRAÇÃO DO RESULTADO

\begin{tabular}{|c|c|c|c|c|c|c|}
\hline \multicolumn{7}{|c|}{ Demonstração do resulto mensal } \\
\hline Sabores & Carne & Frango & Calabresa & Pizza & Queijo & Total \\
\hline $\begin{array}{l}\text { Receita com } \\
\text { vendas }\end{array}$ & $5.400,00$ & $3.600,00$ & $1.800,00$ & $5.400,00$ & $1.800,00$ & $18.000,00$ \\
\hline (-) custo variável & $1.939,82$ & $1.370,36$ & 695,07 & $2.061,32$ & 862,61 & $6.929,18$ \\
\hline (-) despesa variável & 337,50 & 225,00 & 112,50 & 337,50 & 112,50 & $1.125,00$ \\
\hline $\begin{array}{l}\text { (=) margem de } \\
\text { contribuição }\end{array}$ & $3.122,68$ & $2.004,64$ & 992,43 & $3.001,18$ & 824,89 & $9.945,82$ \\
\hline (-) custo fixo & - & - & - & - & - & $3.256,14$ \\
\hline (-) despesa fixa & - & - & - & - & - & $1.019,43$ \\
\hline (=) lucro/prejuízo & - & - & - & - & - & $5.670,25$ \\
\hline
\end{tabular}

Fonte: Desenvolvido pelos autores

Objetivando-se que não ocorressem distorções na margem de contribuição em função da quantidade produzida, optou-se efetuar sua correção por meio se utilizando da função da margem de contribuição multiplicado pelo peso atribuído pela representatividade de sua participação no montante das vendas, resultando em um custo variável médio unitário de $\mathrm{R} \$ \mathbf{0 , 5 5}$, conforme detalhado na tabela abaixo:

Tabela 9. CÁLCULO DA MARGEM DE CONTRIBUIÇÃO

\begin{tabular}{l|r|c|r}
\hline \multicolumn{1}{|c|}{ Produtos } & Margem de Contribuição/un. & PESO & PESO X MC UN. \\
\hline Carne & $\mathrm{R} \$ 0,58$ & 3 & $\mathrm{R} \$ 1,73$ \\
\hline Frango & $\mathrm{R} \$ 0,56$ & 2 & $\mathrm{R} \$ 1,11$ \\
\hline Calabresa & $\mathrm{R} \$ 0,55$ & 1 & $\mathrm{R} \$ 0,55$ \\
\hline Pizza & $\mathrm{R} \$ 0,56$ & 3 & $\mathrm{R} \$ 1,67$ \\
\hline Queijo & $\mathrm{R} \$ 0,46$ & 1 & $\mathrm{R} \$ 0,46$ \\
\hline Total & & & $\mathrm{R} \$ 5,53$ \\
\hline Media & & & $\mathrm{R} \$ 0,55$ \\
\hline
\end{tabular}

Fonte: Desenvolvido pelos autores

Aplicando-se a equação do Ponto Equilíbrio e substituindo suas varáveis, obteve-se um ponto de equilíbrio em quantidades de aproximadamente 5.893 esfihas conforme se demonstra abaixo:

Ponto De Equilíbrio = Custos Fixos / Margem De Contribuição Unitária, logo:

Ponto de Equilíbrio $=3.256,14 / 0,55=>3.892,98$, ou seja, aproximadamente 3.893 unidades. 
Apurado o custo ponto de equilíbrio, é possível dar continuidade a cálculos de outros índices, utilizando do esquema de um balanço patrimonial, obtendo-se dados com o futuro empresário conforme segue:

Tabela 10. BALANÇO PATRIMONIAL

\begin{tabular}{c|r|l|r}
\hline \multicolumn{2}{c|}{ Ativo } & \multicolumn{2}{c}{ Passivo } \\
\hline Circulante & $2.000,00$ & Circulante & 0,00 \\
\hline Disponível & $2.000,00$ & & 0,00 \\
\hline Caixa banco & $2.000,00$ & Não circulante & \\
\hline Não circulante & $8.200,00$ & & $10.200,00$ \\
\hline Imobilizado & $8.200,00$ & Patrimônio Líquido & $10.200,00$ \\
\hline Moto & $3.000,00$ & Capital social & \\
\hline Forno & $1.300,00$ & & \\
\hline Obra & $3.400,00$ & & $10.200,00$ \\
\hline Computador & 500,00 & & \\
\hline Totais & $10.200,00$ & Totais & \\
\hline
\end{tabular}

Fonte: Desenvolvido pelos autores

Conforme afirma o professor PERES JÚNIOR e BEGALLI (2009, p. 262), rentabilidade do ativo total, indica o retorno sobre Ativo Total independentemente de sua procedência, seja dos proprietários (Capital Próprio), das operações da empresa ou de terceiros (Capital de Terceiros).

A utilização deste índice para o estudo de viabilidade se faz necessário para demonstrar o quanto retornará percentualmente para o investidor o capital pelo mesmo investido, considerando-se tanto o capital próprio como o capital de terceiros, em função do resultado obtido pela empresa.

Demonstra-se logo abaixo a rentabilidade apurada:

Tabela 11. CÁLCULO DA RENTABILIDADE

\begin{tabular}{c|c|c}
\hline LUCRO & PATRIMONIO LIQUIDO & RENTABILIDADE \\
\hline R\$ $5.687,43$ & R\$ $10.200,00$ & $5.687,43 / 10.200,00=0,56$ ou $56 \%$ \\
\hline
\end{tabular}

Fonte: Desenvolvido pelos autores

\section{CONCLUSÃO}

Com as dificuldades encontradas pelas pequenas e micros empresas, em se desenvolver e continuar em atividade. A análise de investimento é de maneira essencial para que a mesma possa trilhar esse caminho do melhor modo. Pois é criada de forma técnica, analises e índices para descobrir a viabilidade desta aplicação. 
Em relação aos custos e despesas variáveis gerados na atividade econômica e relacionados ao preço de venda estabelecido para os produtos, confere-se que os produtos geram uma margem de Contribuição. Com essa informação, já sabendo os valores dos custos e despesas fixas, foi possível constituir seu ponto de equilíbrio, que mostrou ser menor que um terço da quantidade esperada de produtos vendidos.

Além deste fator, a importância de depois de identificado o lucro gerado, se relacionado ao investimento previsto. Observa que o lucro é quase sete vezes maior que o investimento, dando a entender que este seria um negócio rentável e totalmente viável ao empreendedor.

Demonstrado também, que esses índices não são tem grandes mudanças negativas caso a empresa se regularize, identificando assim que a empresas para ser viável, não necessite burlar a lei existente.

Desta forma, é verificado que através desse estudo, foi assegurar ao empresário o investimento no negócio, trazendo ao mesmo, maior confiança e melhor visão desse empreendimento, com isso, atingindo os objetivos pré-estabelecidos.

\section{REFERÊNCIAS}

BEUREN, Ilse Maria; et al. Como elaborar trabalhos Monográficos em Contabilidade. Teoria e prática. 3a Ed. São Paulo: Atlas, 2006.

BORNIA, Antonio Cezar. Análise Gerencial de Custos. Aplicação em empresas modernas. 2a Ed. São Paulo: Atlas, 2009.

CORONADO, Osmar. Contabilidade gerencial básica. 2a Ed. São Paulo: Editora Saraiva, 2012.

FREZATTI, Fábio. Gestão de viabilidade econômico-financeira dos projetos de investimentos. São Paulo: Atlas, 2008.

PEREZ JUNIOR, José Hernandez; BEGALLI, Glaucos Antonio. Elaboração da Análise das Demonstrações Contábeis. 4ạ Ed. Livro Digital. São Paulo: Atlas, 2009.

VICECONTI, Paulo; NEVES, Silvério das. Contabilidade de Custos. Um enfoque direto e objetivo. 10å Ed. São Paulo: Editora Saraiva, 2010. 